\title{
La sostenibilidad turística a través de los instrumentos andaluces de planificación ${ }^{1}$
}

\author{
$M^{a}$ Remedios Zamora Roselló \\ Profesora Contratada-Doctora Interina \\ Facultad de Derecho (Universidad de Málaga)
}

\begin{abstract}
SUMARIO: I.-INTRODUGGIÓN. II.-REFERENGIAS NORMATIVAS. II.-PLANES GENERALES: 1. Antecedentes. A. El Plan General de Turismo Sostenible de Andalucía 2008-2011. 2. El Plan General de Turismo Sostenible de Andalucía Horizonte 2020. A. La premisa de la sostenibilidad en el Plan General vigente. B. Las propuestas concretas: líneas estratégicas, programas de actuación y actividades: a) Dinamización. b) Empresariado y empleo. c) Estacionalidad. d) La marca Andalucia. e) Excelencia.f) Innovación. g) Segmentos turísticos. C. Midiendo la sostenibilidad: El Sistema de Indicadores de Desarrollo Turístico Sostenible. IV.-PLANEAMIENTO ESPECÍfICO: 1. La Estrategia Integral de Fomento del Turismo Interior Sostenible de Andalucía. Plan +Interior: a) Lineas estratégicas. b) Programas de actuación. 2. Recualificación de destinos. 3. La Estrategia de Turismo Sostenible. 4. Planes Turísticos de Grandes Ciudades. V.-CONCLUSIONES. VI.-BIBLIOGRAFÍA.
\end{abstract}

\section{I.-INTRODUGCIÓN}

La especial relación de la Comunidad Autónoma de Andalucía con el sector turístico, eje económico y vertebrador de su desarrollo social y territorial, ha obligado a los poderes públicos a dotar a Andalucía de un marco normativo y planificador acorde con las necesidades y desafíos que el turismo presenta ${ }^{2}$.

\footnotetext{
1 Elaborado en el marco del Proyecto de Investigación Ref.DER2013-48329-C2-2-P, financiado por el Ministerio de Economía y Competitividad, Programa Estatal de Fomento de la Investigación Científica y Técnica de Excelencia.

2 El artículo 71 del Estatuto de Autonomía de Andalucía atribuye a la Comunidad Autónoma la competencia exclusiva en materia de turismo que incluye, en todo caso, la ordenación, la planificación y la promoción del sector turístico; funciones que, según lo previsto en el Decreto 12/2015, de 17 de junio, desempeña la Consejería de Turismo y Deporte. Mientras que en el artículo 57 del Estatuto se regulan las competencias autonómicas sobre medio ambiente, espacios protegidos y sostenibilidad. Sobre el esquema de distribución de competencias en el sector turístico, BLANQUER CRIADO, D., “¿Ordenación o desordenación del turismo?" Documentación administrativa, núm. 259 - 260, 2001, pp. 287 - 314; PÉREZ GUERRA, R., "La intervención administrativa en el sector turístico español: La política turística", Revista
} 


\section{CRÓIICTS Y DOCUMEITTOS}

En el Estatuto de Autonomía de Andalucía se establece un claro mandato a los poderes públicos para orientar sus políticas al desarrollo del turismo sostenible, junto a la protección del litoral, la red de espacios naturales protegidos, y el fomento de una tecnología eficiente y limpia. Destacando que "todos los sectores económicos vinculados al desarrollo sostenible cumplen un papel relevante en la defensa del medio ambiente". En el texto estatutario se completa esta referencia con un llamamiento expreso a los "instrumentos adecuados" que han de emplear los poderes públicos para compatibilizar la actividad económica con la óptima calidad ambiental ${ }^{3}$.

La preocupación por la sostenibilidad se ha incrementado paulatinamente, y se ha terminado configurando como un factor clave en los instrumentos autonómicos de planificación ${ }^{4}$. En los últimos años se ha apostado por un modelo turístico que supera la propia concepción de sector económico y que va un paso más allá integrando la perspectiva social, ambiental y cultural. Una de las últimas referencias a la sostenibilidad turística en nuestra Comunidad, nos la encontramos en la "Alianza por un Turismo Innovador y Competitivo en Andalucía”, consensuada por la Administración autonómica, y representantes de los trabajadores y empresarios, se afirma que "en Andalucía aspiramos a un turismo de excelencia y de vanguardia, consolidado desde una perspectiva de sostenibilidad integral y de competitividad como sector estratégico de la economía andaluza, generador de empleo de calidad y desarrollo económico" $"$. Se considera que la sostenibilidad integral y de competitividad para el

Aragonesa de Administración Pública, núm. 43-44, Zaragoza, 2014, pp. 396-413. En relación a las competencias sobre medio ambiente y sostenibilidad en la Comunidad Autónoma de Andalucía, JORDANO FRAGA, J., "Competencias sobre medio ambiente, espacios protegidos y sostenibilidad (Comentario al artículo 57)", en MUÑOZ MACHADO, S., y REBOLLO PUIG, M., (Coords.), Comentarios al Estatuto de Autonomía para Andalucía, Aranzadi, Cizur Menor (Navarra), 2008, pp. 561 - 588.

3 Art. 197 del Estatuto de Autonomía de Andalucía.

La Comisión Europea ya en 2007, elaboró la Agenda para un turismo europeo y sostenible, donde se pronunciaba en los siguientes términos: "El reto consistirá en encontrar un equilibrio adecuado entre el desarrollo autónomo de los destinos y la protección de su medio ambiente por un lado y el desarrollo de una actividad económica competitiva, por otro. Sin embargo, el trabajo del Grupo para la Sostenibilidad del Turismo ha confirmado que, más que cualquier otra actividad económica, el turismo puede desarrollar sinergias por medio de una intensa interacción entre el entorno y la sociedad. Esto se debe a que el desarrollo de destinos turísticos está estrechamente relacionado con su entorno natural, sus especificidades culturales, su interacción social, su seguridad y el bienestar de las poblaciones locales. Estas características hacen del turismo la fuerza motriz para la conservación y el desarrollo de los destinos, tanto directamente, mediante la sensibilización y el apoyo a sus ingresos, como indirectamente, al facilitar una justificación económica para este apoyo por parte de terceros". COMISIÓN DE LAS COMUNIDADES EUROPEAS, Comunicación de la Comisión "Agenda para un turismo europeo y sostenible", COM (2007) 621 final, Bruselas, 19 de octubre de 2007

5 La "Alianza por un Turismo Innovador y Competitivo en Andalucía", fue firmada por los representantes de la Consejería de Turismo y Deporte de la Junta de Andalucía, la Confederación de Empresarios de Andalucía, la Unión General de Trabajadores de Andalucía y Comisiones Obreras de Andalucía, con fecha de 26 de julio de 2016. 
desarrollo turístico de Andalucía debe tener como piezas clave un modelo de crecimiento inteligente, integrador, y sostenible y sostenido. Definiendo la sostenibilidad a partir del uso eficiente de los recursos y de una economía competitiva y sostenida, asentada sobre los productos autóctonos del destino turístico.

A este respecto, cabe la referencia a la definición que ofrece el Código Ético Mundial para el Turismo, y que es una muestra de estos nuevos valores: "El turismo, que es una actividad generalmente asociada al descanso, a la diversión, al deporte y al acceso a la cultura y a la naturaleza, debe concebirse y practicarse como un medio privilegiado de desarrollo individual y colectivo. Si se lleva a cabo con la apertura de espíritu necesaria, es un factor insustituible de autoeducación, tolerancia mutua y aprendizaje de las legítimas diferencias entre pueblos y culturas y de su diversidad. Las actividades turísticas respetarán la igualdad de hombres y mujeres. Asimismo, se encaminarán a promover los derechos humanos y, en particular, los derechos específicos de los grupos de población más vulnerables, especialmente los niños, las personas mayores y minusválidas, las minorías étnicas y los pueblos autóctonos" ${ }^{\text {. }}$

\section{II.-REFERENCIAS NORMATIVAS}

La Ley del Turismo de Andalucía, aprobada en 1999, hizo especial hincapié en la ordenación y promoción del turismo y creó una base planificadora del sector; sobre la premisa de apostar por un crecimiento ordenado y sostenible, con especial atención a la necesidad de proteger el medio natural y el patrimonio histórico y cultural.

El principal instrumento de planificación era el Plan General del Turismo, que según la Exposición de Motivos de esta disposición, se encontraba "llamado a definir el modelo y la estrategia de desarrollo turístico de la Comunidad Autónoma, sin perjuicio de su eventual desarrollo, con relación a sectores específicos, a través de programas ejecutivos".

Tras una década de aplicación de esta norma, el legislador andaluz optó por la elaboración de la Ley 13/2011 desde la que se ha proyectado la relevancia de los as-

$6 \quad$ El Código Ético Mundial para el Turismo fue aprobado por unanimidad en la XIII ${ }^{\text {a }}$ reunión de la Asamblea General de la Organización Mundial del Turismo en Santiago de Chile, en octubre de 1999, y refrendado por la Asamblea General de las Naciones Unidas el 21 de diciembre de 2001, con la resolución A/RES/56/212.

A principios de 2016, la Organización Mundial del Turismo y la Red Española de Pacto Mundial adoptaron un acuerdo de colaboración para implicar a las empresas del sector turístico en iniciativas de responsabilidad social corporativa. Esta iniciativa se denomina "Turismo responsable: un compromiso de todos", e incluye la firma del Código Ético Mundial para el Turismo y de los 10 Principios del Pacto Mundial por parte de compañías del sector turístico. 


\section{CRÓHICAS Y DOCUMEITOS}

pectos territoriales, ambientales y paisajísticos, para el nuevo modelo de ordenación de los recursos turísticos. Esta ordenación comprende una serie de instrumentos de planeamiento que, en gran medida, mantienen las líneas básicas de la ley de 1999.

Al trazar como objeto de la norma la ordenación, planificación y promoción del turismo sostenible, el legislador andaluz va un paso más allá en la regulación de este sector estratégico para la economía andaluza. El principio de sostenibilidad es clave a lo largo de todo el articulado, y se establece un mandato expreso a las Administraciones Públicas para que destinen sus esfuerzos a la mejora de la calidad y la competitividad de la oferta turística andaluza sobre la base de la sostenibilidad.

Entre las acciones previstas para la consecución de estos fines, y que están llamadas a guiar las acciones de ordenación y fomento desarrolladas por los poderes públicos, debemos señalar algunas actuaciones que inciden en la aplicación del principio de sostenibilidad.

En lo que respecta al medio rural y al espacio litoral, la Ley andaluza establece un modelo de desarrollo turístico sostenible sobre la base de las características diferenciales del territorio. Igualmente, debemos señalar el establecimiento de criterios generales y recomendaciones para la consideración y tratamiento del paisaje en la política turística ${ }^{7}$.

Otro de los aspectos claves es el uso del suelo, apostando por un uso eficiente y sostenible, en el que se valoren adecuadamente los espacios que han de ser destinados a uso turístico. En esta misma línea, nos encontramos con la necesidad de dar respuesta a las demandas de conservación de aquellos espacios culturales y naturales que son masivamente visitados, y que necesitan una actuación planificadora específica que permita garantizar su integridad ambiental y su nivel de conservación.

La eficiencia energética como elemento de la sostenibilidad se pone de manifiesto a través de la renovación de las edificaciones e instalaciones de los establecimientos turísticos, apostando por la inclusión de mejoras técnicas que también permitan una adecuada gestión de residuos.

En relación a la relevancia del paisaje como materia prima del sector turístico, HILDENBRAND SCHEID, A., "La Estrategia de Paisaje de Andalucía y el turismo", Curso de Verano: La sostenibilidad de los entornos turísticos, Universidad de Málaga, 2012. 


\section{III.-PLANEAMIENTO GENERAL}

\section{Antecedentes}

Desde la elaboración del Plan DIA, a principios de los años noventa del pasado siglo, se han sucedido los instrumentos de planificación que han trazado las directrices sobre el modelo turístico a implantar ${ }^{8}$. En este primer texto ya se incluía una referencia a la consecución de la rentabilidad ambiental, que había de marcar la política autonómica. Si bien, este primer plan de ordenación turística para la Comunidad estuvo en gran parte condicionado por la recesión económica y la crisis del sector; lo que permite entender la acepción de rentabilidad que se añadía a la perspectiva ambiental.

El instrumento clave que crea la norma de 1999 para la ordenación de los recursos turísticos es el Plan General del Turismo; texto destinado a concretar las necesidades, objetivos, prioridades y programas de acción, definir el modelo y la estrategia de desarrollo turístico, y fomentar los recursos turísticos de Andalucía. Es relevante el análisis de la regulación de 1999, porque por vez primera se regula el marco de actuación del sector turístico; el Plan General que ha de trazar las líneas generales y de futuro, condicionando el desarrollo a medio y largo plazo. Este modelo de planificación, marcada por un plan general, se ha mantenido en la regulación vigente.

En el año 2003 se adoptó el primero de los planes generales de turismo, este texto aspiraba a la consolidación del sector turístico como elemento clave del desarrollo de la Comunidad ${ }^{9}$. Para ello, se centraba en tres objetivos intermedios, que no incluían referencia directa a la perspectiva ambiental; centrándose en la mejora de la competitividad, la renovación del modelo turístico, y la integración del turismo en la sociedad. Había que esperar a las estrategias que concretaban estos objetivos básicos para encontrar la referencia a la perspectiva ambiental.

El concepto de sostenibilidad que empleaba este texto, era de aplicación a las dimensiones culturales y ambientales, relacionadas con la competitividad y la integración equilibrada del turismo en el marco territorial. No obstante, las medidas concretas no hacían referencia a la sostenibilidad cultural, ni al ámbito territorial,

8 Sobre las previsiones normativas del sector turístico con referencia a la protección de los recursos, CEBALLOS MARTÍN, M., y PÉREZ GUERRA, R., "Aproximación evolutiva en la protección de los recursos naturales y culturales a través de la legislación turística", en RODRÍGUEZ ARANA MUÑOZ, J., y DEL GUAYO CASTIELLA, I., Panorama jurídico de las administraciones públicas en el siglo XXI: Homenaje al profesor Eduardo Roca Roca, Instituto Nacional de Administración Pública, Madrid, 2002, pp. 271-294.

9 La formulación del Plan General de Turismo fue adoptada por el Consejo de Gobierno mediante el Decreto 22/2002, de 29 de enero. Por Decreto 340/2003, de 9 de diciembre, fue aprobado el Plan General de Turismo de Andalucía 2003-2006 (BOJA núm. 9, de 15 de enero de 2004). 
sino que se centraron en la perspectiva ambiental; a pesar de que la sostenibilidad se definía como uno de los referentes esenciales de la actividad turística.

Las medidas integradas en esta estrategia se concretaron en el desarrollo de un sistema de indicadores ambientales y sostenibilidad del turismo, la elaboración de los planes de recualificación de destinos, la creación de una línea de ayuda para la mejora de la calidad ambiental en las empresas turísticas, y la aprobación de la Agenda 21 del turismo en Andalucía.

A. El Plan General de Turismo Sostenible de Andalucía 2008-2011

La aprobación del Plan General de Turismo Sostenible de Andalucía 20082011, supuso un punto de inflexión en la regulación; por vez primera se incluía la sostenibilidad en la propia denominación del Plan; de esta forma, desde la Administración autonómica se ponía de relieve que la sostenibilidad era un elemento transversal, incorporado a cada una de las estrategias, programas y medidas ${ }^{10}$.

El Plan se estructuraba en tres pilares: la adecuación del espacio turístico, la convergencia de políticas pública y la concertación social, y la actuación en marketing y productos centrada en segmentos específicos. Estos tres ámbitos de intervención no suponían una novedad, puesto que se correspondían con algunos de los fines ya previstos en los planes precedentes ${ }^{11}$.

Los objetivos generales se determinaron en el Decreto de formulación del año 2005 y se concretan en el desarrollo de un modelo turístico sostenible y competitivo, una política turística basada en la diferenciación, y en un proceso de integración entre planificación y gestión; sin olvidar el fortalecimiento del sector empresarial turístico y la creación de empleo.

Los objetivos específicos son: la redefinición del posicionamiento competitivo, la adecuación de la estructura productiva a las nuevas necesidades, y la mejora de la coherencia y la eficacia en la actuación conjunta. Estos tres objetivos se desarrollaron a través de orientaciones estratégicas, entre las que vamos a destacar las que inciden en mayor medida sobre la sostenibilidad.

10 En relación a los caracteres de este instrumento de planificación, RIVAS GARCÍA, J., y MAGADÁN DÍAZ, M., Planificación y Gestión Sostenible del Turismo, Septem Ediciones, Oviedo, 2015, pp. 132 y ss.

11 Como afirma SOCÍAS CAMACHO, J., "Planificación territorial, medio ambiente y turismo: hacia un turismo sostenible", XXI Congreso Italo-español de Profesores de Derecho Administrativo, Alicante/Benidorm, 26-28 de mayo de 2016, p. 5: "Turismo responsable, competitivo y de calidad, en definitiva, turismo próspero y sostenible, es el gran reto de la Administración frente al turismo del siglo XXI, que debe alcanzarse a partir de la revalorización de los destinos turísticos, la incorporación de la nueva gestión del marketing turístico a partir de las tecnologías de la información y el establecimiento de medidas de unidad de mercado impuestas por la Unión Europea". 
Ente las orientaciones que configuraron el objetivo de redefinición del posicionamiento competitivo cabría destacar el impulso del "desarrollo basado en la diferencia a partir del reforzamiento de la identidad del espacio turístico basada en el patrimonio natural, cultural y paisajístico"; en definitiva, la puesta en valor de los recursos naturales, culturales..., que conforman el espacio turístico andaluz. Elementos que se encuentran vinculados a los recursos patrimoniales propios y que, paradójicamente, han sido parcialmente devastados por la industria turística. A fin de contrarrestar estos efectos, desde el Plan se auspiciaban las medidas dirigidas a la identificación y/o recuperación de los elementos identitarios de los destinos turísticos, así como a la cohesión y valoración del espacio turístico, que incidan en atractivos basados en estos elementos.

En el segundo de los objetivos, que agrupa las iniciativas para la adecuación de la estructura productiva a las nuevas necesidades, debemos destacar una orientación básica, que afecta a todos los sectores implicados, y se dedica al "desafío de la calidad total". Esta orientación parte de las previsiones del Plan de Calidad Turística de Andalucía 2006-2008, destacando los criterios de sostenibilidad y las consecuencias derivadas del cambio climático.

También se incluía una orientación estratégica destinada al fomento de una "cultura innovadora en productos y procesos en un entorno de integración ambiental". A fin de potenciar la compatibilidad entre la actividad económica y la protección del medio, se distingue entre medio urbano y los entornos naturales. Mientras que en el medio urbano se prima el mantenimiento de los valores patrimoniales de identidad y de promoción de la sostenibilidad; en el medio natural, se apuesta por el respeto a los ecosistemas y al patrimonio cultural y paisajístico.

La mejora de la coherencia y la eficacia en la actuación conjunta, tercero de los objetivos, comprende un conjunto estrategias encaminadas a coordinar las políticas culturales, ambientales, comerciales y deportivas de la Junta de Andalucía con la política turística; además de las referencias a las políticas de ordenación del territorio, urbanismo y obras públicas.

La colaboración entre la política de control ambiental y la turística constituye el fin último de una orientación estratégica que presenta una percepción de la sostenibilidad novedosa en el Plan, ya que se analiza como un elemento de competitividad. De esta forma, se apuesta por un refuerzo de la sostenibilidad como vía para mejorar la competitividad del sector en aquellos mercados con un alto grado de sensibilización en materia de integración ambiental. 


\section{El Plan General de Turismo Sostenible de Andalucía} Horizonte 2020.

Mediante el Decreto 37/2016 de la Consejería de Turismo y Deporte se aprobó el Plan General de Turismo Sostenible de Andalucía Horizonte 2020, instrumento de referencia para la ordenación de los recursos turísticos en la Comunidad Autónoma, y piedra angular sobre la que ha de elaborarse la política turística y los instrumentos de planeamiento que rigen el sector turístico.

El objetivo central de este Plan es "consolidar la sostenibilidad integral y la competitividad del turismo como sector estratégico de la economía andaluza, generador de empleo de calidad y desarrollo económico".

Con el PGTS Horizonte 2020 se trata de ofrecer una respuesta a los diez retos del sector turístico en Andalucía, definidos a través de sesiones de trabajo entre la Administración autonómica y el sector turístico andaluz ${ }^{12}$. Cabe destacar que el primero de estos retos es la promoción de la sostenibilidad integral del destino, minimizando los impactos negativos que se derivan de las actividades turísticas y fomentando los positivos. Asimismo, nos encontramos con referencias a la necesidad de fortalecer la cooperación público-privada y la coordinación interadministrativa, a la vez que se debe generalizar el uso de las nuevas tecnologías, y se aspira a la consecución de la excelencia y calidad total del destino turístico andaluz, entre otros retos.

En el Decreto 38/2013, por el que se aprueba la formulación del Plan ya se especificaban cuáles habían de ser los objetivos generales de este texto. Entre los fines previstos, podemos destacar la necesidad de "definir estrategias y políticas para implementar un modelo de desarrollo turístico sostenible, viable, equitativo, competitivo e igualitario desde una perspectiva de género, que haga un uso óptimo de los recursos disponibles, respetuoso con los valores locales y los espacios donde se desarrolla el turismo y que garantice la cohesión territorial".

A. La premisa de la sostenibilidad en el Plan General vigente.

Puesto que nuestro estudio se centra en el análisis de la sostenibilidad en los instrumentos de planificación, debemos remitirnos a la definición que al respecto nos ofrece el Acuerdo alcanzado en el IV Pacto Andaluz por el Turismo, donde se afirmaba que "la base para el desarrollo sostenible de la actividad turística y de la propia Comunidad Autónoma, se encuentra en el entendimiento e implementación de la sostenibilidad en un sentido integral, teniendo en cuenta no sólo los aspectos

12 Estos retos fueron el resultado de la "Conferencia Estratégica del Turismo", celebrada en Torremolinos (Málaga), el 22 de noviembre de 2012, y de las "Jornadas Provinciales de Planificación Estratégica", organizadas a lo largo del mes de junio de 2013 en todas las capitales andaluzas. 
ambientales, económicos y sociales, sino otras dimensiones y procesos (culturales, institucionales, territoriales, tecnológicos, participativos, etc.), sin los cuales no podría ser realmente sostenible (...) es importante poner de relieve que un turismo ordenado favorece la sostenibilidad".

Es relevante esta definición por cuanto nos muestra un concepto amplio de sostenibilidad, y que claramente apuesta por la planificación como instrumento para su consecución. En definitiva, nos encontramos ante la evolución lógica de la actividad turística, que parte de la necesidad de integrar este modelo productivo dentro del esquema territorial de la Comunidad Autónoma; además de poner de relieve las múltiples facetas de este sector, y que también deben ser analizadas y desarrolladas desde la perspectiva de la sostenibilidad ${ }^{13}$.

Para la elaboración de este Plan se ha tomado como referencia este concepto amplio de desarrollo sostenible, al que también se le han incluido otros aspectos como la sostenibilidad paisajística o la gobernanza. Se aspira a ofrecer un concepto renovado de sostenibilidad integral que sea práctico y con una clara vocación de aplicación $^{14}$.

Siguiendo estas premisas, desde el Plan se opta por un crecimiento que se asienta sobre tres ejes: el turismo, los recursos y la población. De forma que la oferta turística de la Comunidad Autónoma ha de pasar por integrar la conservación y protección de los recursos que alberga el territorio autonómico; además de incorporar a la población local como elemento determinante de la experiencia turística, apostando por la calidad de vida de los residentes en las poblaciones locales, y la calidad en la experiencia turística para los visitantes.

13 Otras Comunidades Autónomas también han integrado la sostenibilidad como una de las prioridades en sus instrumentos de planificación turística. A este respecto, podemos citar el Plan Estratégico de Turismo de Cataluña 2013-2016, donde se afirma que "el principal reto que debe afrontar Cataluña como destino turístico es el de equilibrar la cantidad con la calidad del turismo, atrayendo un turismo de mayor valor añadido que permita asegurar la sostenibilidad económica, social y ambiental de cara al futuro. Sin embargo, la consecución de este reto principal pasa previamente por considerar otros retos fundamentales". Entre los retos que incluye este Plan, se hace referencia al "reto del desarrollo sostenible", y se indica "aspectos como un urbanismo agresivo, el poco respeto hacia el paisaje, la creación de camas turísticas sin valor añadido, la falta de innovación empresarial, la ausencia de reinversión o el monocultivo turístico han conllevado que en ciertos destinos el coste económico, social y ambiental que representan algunos segmentos de turistas sea superior a los beneficios que generan. Por lo tanto, en primer lugar, deben identificarse los destinos o las empresas que fundamentan su modelo turístico o modelo de negocio en criterios insostenibles, como paso previo a influir en un proceso de transformación obligatoria hacia modelos sostenibles. En este apartado, debe incidirse especialmente en asegurar una adecuada movilidad turística, tanto de acceso como interna, entre los diferentes destinos del país".

14 BOUAZZA ARIÑO, O., "Criterios para un desarrollo territorial sostenible del turismo", $\mathrm{El}$ derecho urbanístico del siglo XXI: Libro homenaje al profesor Martín Bassols Coma, vol. 2, Editorial Reus, Barcelona, 2008, pp. $156-190$. 


\section{CRÓHICAS Y DOCUMEITOS}

Desde el texto del Plan se apuesta por la sostenibilidad "como un proceso continuo de desarrollo armónico con el medio", en lugar de su consideración como un fin en sí mismo. De ahí la necesidad de sustituir el concepto de "sostenibilidad" por el de "desarrollo turístico sostenible". Los principios rectores del plan tratan de dar respuesta a estos objetivos mediante la implantación de un conjunto de procesos relativos a: la producción de servicios turísticos eficiente y equitativo, la defensa de los valores locales, la cohesión territorial, un proceso continuo de innovación para la calidad y la excelencia, la apropiación de la actividad turística por parte de la ciudadanía, y un proceso de gobernanza basado en la transparencia, la participación y la codecisión.

Entre los principios rectores del plan debemos destacar aquellos que más directamente inciden en la consecución de un modelo turístico sostenible. En primer lugar, las referencias a la defensa de los valores locales y a la integración de la ciudadanía en la actividad turística. Estos dos principios merecen una valoración conjunta por cuanto presentan una serie de singularidades comunes: los residentes de cualquier localidad andaluza que reciben a los visitantes, bien de forma esporádica, o bien regularmente, deben sentirse beneficiados directos de esta actividad.

Es un desafío que no conciban al turismo como un lastre que satura sus equipamientos e infraestructuras, por lo que se ha de invertir en la calidad desde todas las perspectivas de la actividad turística. De esta forma, la población, uno de los ejes del Plan, actuará como la mejor embajadora de los valores locales; apoyando las iniciativas de la administración turística para desarrollar una oferta de productos y experiencias que responda a las demandas del sector; integrando al turista en sus localidades.

Los valores a los que hace referencia el Plan incluyen la perspectiva ambiental, cultural, histórica, etc., y se configuran como el principal atractivo del destino turístico. La implantación de un modelo de desarrollo sostenible exige que el disfrute de estos recursos por parte de los ciudadanos y los visitantes no implique su degradación ni desaparición, sino su puesta en valor y protección.

El desigual desarrollo turístico del territorio andaluz implica una desafío para la cohesión territorial; de ahí, la necesidad de un modelo equilibrado y complementario de los distintos territorios andaluces. Este principio supone un reto para la administración turística, por cuanto ha de ser capaz de elaborar una política turística que ofrezca respuestas a necesidades dispares, sin por ello obviar la construcción de una apuesta conjunta amparada en el destino Andalucía. Mientras aquellos territorios que acaban de incorporarse a la explotación turística necesitan de un asesoramiento y guía vinculado a la dinamización del destino; otros espacios andaluces con una marcada tradición en el ámbito turístico están llamados a la inevitable recualifi- 
cación y ordenación a las últimas demandas del sector, y para su adecuación a los actuales estándares de calidad.

El Plan apuesta porque los destinos consolidados actúen como reclamo, para después acercar al visitante a otros espacios todavía desconocidos para el turismo; esta premisa no puede significar que todo el territorio andaluz ha de convertirse en un destino turístico de primer nivel y relevancia internacional. Los recursos de cada espacio condicionarán la actividad que pueda producirse, contexto que permitirá un modelo real de desarrollo sostenible en la Comunidad, no sólo en lo que respecta al sector turístico, sino a las directrices para el desarrollo socioeconómico de Andalucía. De lo contrario, estaríamos supeditando los valores locales a la implantación de un modelo turístico vacío de contenido.

B. Las propuestas concretas: líneas estratégicas, programas de actuación y actividades.

Las directrices del Plan vienen definidas en las denominadas "líneas estratégicas", que marcan el contenido de los distintos programas de actuación, donde se definen las medidas concretas a desarrollar por este instrumento de planificación y se establecen las bases de la política turística autonómica. El Plan se concreta en treinta programas de actuación; para cada uno de estos programas se especifica su nivel de vinculación con las líneas estratégicas, su objetivo, una descripción, las actividades que se realizarán en desarrollo del programa, los resultados esperados y las fuentes de financiación.

Si bien en el Plan aparecen diferenciadas, hemos optado por su análisis conjunto agrupadas por materias, para comprender mejor cómo se va a concretar el desarrollo de las políticas comunitarias en cada una de las prioridades definidas.

\section{a) Dinamización}

La dinamización integral y cooperativa del sector turístico andaluz es el objetivo de la primera línea estratégica, y se configura como una apuesta por la coordinación de las Administraciones Públicas y de los sectores de actividad que confluyen en el turismo. El fin último es el fomento de productos y experiencias que sean singulares y únicos, para lo que se fundamenta en un trabajo integral de los agentes, destinos y actores implicados, tanto públicos como privados. Como ya hemos señalado, la sostenibilidad pasa por la ordenación del sector y, por ende, por la eficacia y eficiencia que muestren las políticas autonómicas y las iniciativas privadas. De ahí la necesidad de coordinar los esfuerzos para ofrecer el mejor destino, con un claro respeto por el entorno y las demandas de la población local.

La accesibilidad administrativa es la temática de uno de los programas de actuación que da respuesta a esta línea estratégica, y que aspira al establecimiento de 
procedimientos administrativos ágiles y cercanos; así como a hacer pública y accesible la información turística a través de espacios de cooperación ${ }^{15}$.

Entre los programas de actuación relacionados, podemos destacar el dedicado a la adecuación entre planificación y gestión, cuya finalidad es adecuar la práctica de la gestión pública del turismo a los instrumentos de planificación aprobados por la Consejería de Turismo y Deporte. El objetivo último es dotar de coherencia a las políticas turísticas públicas, y fomentar la participación en la aplicación de los instrumentos de planificación.

Mediante el programa destinado a la coordinación administrativa y cooperación público-privada, se persigue implementar mecanismos estables de colaboración entre las Administraciones Públicas competentes y los empresarios del sector. Con el desarrollo de este programa se espera la consecución de un adecuado grado de coherencia entre las políticas de protección del patrimonio y la utilización de los recursos; además de conseguir que los agentes privados se impliquen en la creación de una red de información de los activos turísticos andaluces. Destacamos de este programa la integración de los agentes privados en la conservación de los recursos; la protección de los valores locales pasa por la participación de todos los sectores implicados, desde la ciudadanía hasta las Administraciones Públicas, pasando por los trabajadores y empresarios del turismo.

\section{b) Empresariado y empleo}

La segunda y tercera de las líneas se destinan al tejido empresarial y a la estabilidad y calidad del empleo. Es de interés un estudio conjunto de estas dos estrategias del Plan por cuanto tienen en común la finalidad de incrementar la riqueza y el empleo en la Comunidad Autónoma, sobre la base de una inversión en la modernización y actualización del tejido empresarial, y de una mejora en la cualificación y las condiciones laborales de los trabajadores dedicados a la actividad turística. La mejora en la competitividad del sector pasa por el impulso a las nuevas tecnologías y al emprendimiento, destinados a la creación y difusión de productos turísticos que permitan atender las demandas del sector durante todo el año; y ofrezcan una respuesta de calidad a un turista maduro, en lo que respecta a su conocimiento del destino y a la demanda de experiencias.

15 JIMÉNEZ SOTO, I., "Ordenación de los servicios turísticos: competencias administrativas y unidad de mercado", XXI Congreso Italo-español de Profesores de Derecho Administrativo, Alicante/Benidorm, 2628 de mayo de 2016, p. 28. Este autor destaca el esfuerzo de las Comunidades Autónomas para incorporar la Directiva de Servicios y, por tanto, adoptar medidas para la simplificación de trámites y procedimientos a la hora de regular sus servicios turísticos. 
La calidad del producto es también el resultado de la calidad en el empleo y de la profesionalización, pues aún subsisten deficiencias subsanables en materia de condiciones laborales y atención al visitante. La integración de la ciudadanía es una clave para la consecución de un modelo turístico sostenible; un empleo de calidad y la creación de riqueza en la Comunidad son un buen ejemplo de las expectativas que genera el sector en la población local.

Entre los programas de actuación relacionados con estas líneas estratégicas cabe destacar el dedicado a la internacionalización, mediante el que se fomenta la consolidación de la posición exterior de las empresas andaluzas y su expansión en el extranjero. La finalidad de este programa es trasladar al empresariado la necesidad de su expansión a nuevos mercados, principalmente en los emergentes. Desde la administración autonómica se incluyen una serie de iniciativas que facilitan esta proyección exterior de las empresas andaluzas a través de una doble perspectiva: mediante el asesoramiento especializado sobre las caracteres de fiscalidad, regulación, etc., de estos nuevos mercados, y que se terminan convirtiendo en obstáculos para las empresas; y, por otro lado, mediante incentivos económicos y formativos para los agentes con menor capacidad de proyección internacional, especialmente pequeñas empresas y autónomos.

Para el impulso de nuevas iniciativas empresariales se ha desarrollado un programa de apoyo al emprendimiento turístico sostenible y competitivo; se incentivan las actuaciones en sectores emergentes y competitivos, con especial atención a la innovación tecnológica y a la singularidad de los productos y servicios ofertados. Para los jóvenes emprendedores también se prevé un soporte específico desde la administración turística a través de una red de apoyo público.

"A fin de mejorar el empleo, los programas de actuación se centran en la promoción laboral de colectivos desfavorecidos o en riesgo de exclusión social, logrando una mayor cohesión social en la actividad turística. También se destina un programa de formación para la profesionalización de los recursos humanos, cuya finalidad es eliminar las deficiencias formativas tanto en el ámbito laboral como en el empresarial, y conseguir un mayor nivel de profesionalización y especialización del sector turístico".

Desde la administración turística se ha configurado un programa de apoyo normativo a las empresas turísticas para el mantenimiento de un empleo estable y de calidad, mediante el establecimiento de beneficios a las empresas que se distingan por el mantenimiento del empleo a lo largo de todo el año. Con este programa, los resultados se dirigen de nuevo hacia la profesionalización y especialización del sector, así como a la consecución de un mayor grado de competitividad; además de apoyar a las empresas acreditadas, en detrimento de la oferta turística ilegal. 


\section{CRÓHICAS Y DOCUMEITOS}

\section{c) Estacionalidad}

Vinculada a la calidad en el empleo y al aprovechamiento de los recursos turísticos, se encuentra la siguiente de las líneas estratégicas dedicadas a la estacionalidad; uno de los desafíos que arrastra el sector turístico andaluz desde hace décadas y que aún en la actualidad se ha de reflejar en el planeamiento general. La inactividad en la temporada baja genera un empleo de escasa calidad y una desocupación de las infraestructuras turísticas.

La política autonómica a este respecto se dirige a atraer a colectivos que puedan visitar el destino Andalucía en temporada baja, específicamente mayores y jóvenes, y el turismo de reuniones y congresos. Las propuestas se centran en la creación de productos específicos para estos visitantes, un conjunto de medidas de promoción y comercialización, y la implantación de incentivos económicos y fiscales destinados a las empresas que continúen ofreciendo sus servicios fuera de temporada.

El Plan dedica un apartado específico al turismo de reuniones, y se crea un programa para ofrecer paquetes turísticos con el fin de promover la complementariedad de destinos, segmentos turísticos, actividades y sectores económicos. En desarrollo de este programa se crea un organismo integrador de los equipamientos de turismo de reuniones y congresos, así como generar la marca "Andalucía Congresos" para elaborar estrategias de promoción y comercialización.

Los programas que tratan de acabar con la estacionalidad se centran en segmentos y productos turísticos con motivaciones no estacionales, y persiguen la apertura de establecimientos de alojamiento y otras infraestructuras turísticas durante todo el año; a la vez que potencian iniciativas no ligadas a las fechas tradicionales para la llegada de los visitantes.

Desde otros frentes también se aborda el impulso del turismo fuera de temporada, como son los programas de promoción y comercialización de productos turísticos segmentados por temporadas, y de productos turísticos diversificados fuera de temporada alta. Mediante estas iniciativas se consolidan las herramientas virtuales de promoción y comercialización para incrementar el valor añadido del destino y favorecer la interactividad, y se proponen medidas para que los turistas nacionales y extranjeros conozcan los productos turísticos que durante todo el año pueden disfrutarse.

Uno de los programas más interesantes, por la integración de los criterios de sostenibilidad, es el dedicado a la concienciación institucional para la gestión de la estacionalidad del sistema turístico andaluz. El objetivo es cambiar los hábitos vacacionales de los turistas españoles con la desconcentración de los periodos de ocio, específicamente a través de su disminución en el periodo estival y su correlativo au- 
mento el resto del año. El modelo que se sigue es el de otros países de nuestro entorno, que no concentran las vacaciones en la etapa estival. Se apuesta por los acuerdos con la Administración educativa para replantear el calendario escolar y universitario; así como fomentar la redistribución de los periodos vacacionales en el sector público y las grandes corporaciones.

Entre los resultados esperados, además de reducir el cierre estacional de los establecimientos turísticos, se aspira a la consecución de un mayor grado de sostenibilidad de los espacios turísticos, la mejora en el aprovechamiento de las infraestructuras y la reducción de los periodos de ocupación intensiva. Este programa es interesante por cuanto apuesta por una iniciativa original para el tratamiento de la estacionalidad en el mercado nacional; reforzada por la experiencia de la redistribución del ocio en otros países, y que supone una aportación clara a la sostenibilidad del destino Andalucía a través de la explotación racional de los recursos. Evitar la saturación supone incrementar los niveles de calidad y de satisfacción del turista, mejorar la generación de riqueza y el empleo, reducir los efectos negativos de la masificación turística sobre las poblaciones locales, y garantizar la mejora en la preservación y conservación de los recursos, con especial atención a los naturales y monumentales.

\section{d) La marca Andalucía}

Al refuerzo y posicionamiento de la marca Andalucía se destina la quinta de las líneas estratégicas del Plan; desde el punto de vista de la competitividad, se apuesta por la consolidación de su liderazgo en el mercado nacional y en el extranjero, junto con un impulso a las iniciativas adoptadas en los mercados emergentes para alcanzar mejores cuotas de visitantes.

La voluntad de la administración autonómica es asociar la imagen de marca de Andalucía con un modelo turístico de calidad, en el que se pongan de manifiesto las singularidades de un territorio que ofrece un conjunto de recursos históricos, culturales, paisajísticos y gastronómicos que no sólo ponen de relieve la riqueza de Andalucía si no que constituyen una muestra de la voluntad de conservación y recuperación de los valores locales. En este sentido, de nuevo nos encontramos con una muestra de la sostenibilidad integrada en una línea estratégica del Plan; la finalidad es realzar los valores que identifican a la Comunidad Autónoma y posicionarlos en el mercado turístico desde el respeto y la premisa de su conservación, elementos que se identifican con el modelo de calidad que ha de primar en la marca Andalucía.

\section{e) Excelencia}

Calidad y excelencia son dos claves en la consolidación de un modelo turístico sostenible de primer nivel, como es el destino turístico Andalucía; por ello, la siguiente de las líneas estratégicas se centra en la consolidación de la excelencia en la 
actividad turística, a través de la adecuación del destino a las demandas del turista, y su constante adaptación en función a la satisfacción de sus expectativas. En este contexto, la sostenibilidad se consolida a través de la apuesta por la universalidad del turismo gracias a las medidas de accesibilidad física. Esta iniciativa se centra en que todos los visitantes, con independencia de sus características y necesidades, disfruten en igual medida de los recursos turísticos de Andalucía.

La accesibilidad universal completa es objeto de un programa específico, dedicado a la supresión de las barreras que dificulten la estancia de turistas con discapacidad y la creación y desarrollo de productos específicos ${ }^{16}$.

Siguiendo esta línea estratégica se encuentra el programa destinado al posicionamiento del destino a través de la investigación en los mercados de origen. Se trata de consolidar el posicionamiento de la marca Andalucía en el mercado internacional, y mejorar la percepción del destino en origen.

Como garantes de la calidad y excelencia, e impulsores en el cumplimiento de los derechos y garantías de todos los turistas, destacan las medidas de inspección y control. El Plan incluye un programa de actuación dedicado a la calidad de la estancia turística en Andalucía. Su finalidad es la defensa y protección de los derechos de los usuarios turísticos, para alcanzar la plena satisfacción en relación a los servicios turísticos recibidos y resolver con rapidez los problemas que puedan surgir durante la estancia.

\section{f) Innovación}

El Plan se centra en las nuevas tecnologías aplicadas a la mejora de la competitividad, gracias al mejor conocimiento del turista y al interés en acercar la marca Andalucía a un visitante que emplea la tecnología para la preparación de su viaje, durante su estancia y también para compartir el resultado de su experiencia a través de las redes sociales ${ }^{17}$.

La implantación de un turismo sostenible pasa por la aplicación de la innovación tecnológica a otros campos como son la mejora de las instalaciones con equipa-

16 Sobre la accesibilidad en el sector turístico, SORET LAFRAYA, P., y BARRAGÁN ITURRIAGA, A., "Turismo accesible y legislación”, Estudios Turísticos, núm. 203-204, 2015, pp. 75 - 85.

17 En relación a la necesidad de replantear el modelo de intervención administrativa a la vista de las novedades introducidas por el empleo de las nuevas tecnologías, BAUZÁ MARTORELL, F., "Intervención administrativa, turismo y medios técnicos", XXI Congreso Italo-español de Profesores de Derecho Administrativo, Alicante/Benidorm, 26-28 de mayo de 2016. Este autor afirma: "La irrupción y desarrollo de las nuevas tecnologías ha dado lugar a una suerte de control privado sobre la actividad (en este caso) turística, de manera que el control de los agentes públicos ha dejado de ser único y exclusivo, hasta el punto que en muchos casos una crítica de un usuario en un portal digital resulta más efectiva que una sanción administrativa" (p. 2). 
mientos que ahorren los costes energéticos y materiales respetuosos con el entorno. Uno de los elementos que ha de guiar las actividades que conforman esta línea estratégica es la política sobre cambio climático; el turismo y los recursos sobre los que se fundamenta son uno de los principales afectados por sus efectos. De ahí, la necesidad de concienciar a los operadores del sector turístico sobre la necesidad de aplicar este tipo de iniciativas ${ }^{18}$. En este sentido, la Comunidad Autónoma de Andalucía es una de las pioneras a nivel nacional en la adopción de programas y actuaciones concretas que tratan de paliar sus efectos, y que inciden en la lucha contra el cambio climático; a diferencia de buena parte de los planes turísticos a nivel nacional y autonómico ${ }^{19}$.

Asimismo, y en la senda de las previsiones sobre accesibilidad incluidas en la línea sexta, las nuevas tecnologías representan una oportunidad para mejorar la experiencia turística de personas con limitaciones físicas que pueden disfrutar de productos turísticos adaptados a sus necesidades.

El programa de apoyo a la calidad y fomento de la sostenibilidad en las infraestructuras turísticas, persigue un mayor nivel de concienciación en materia de eficiencia energética, a la vez que sitúa entre sus resultados una mejora de la calidad ambiental de los destinos turísticos de Andalucía. En lo que respecta a las infraestructuras de alojamiento, el programa tiene por objetivo la renovación de la planta hotelera regional y el incremento de la calidad.

Relacionados con esta línea estratégica también nos encontramos con el programa de utilización de las nuevas tecnologías en la promoción y comercialización turística, y el programa destinado a la generalización del uso de las nuevas tecnologías en el turismo.

La investigación aplicada al sector turístico es una herramienta imprescindible para el análisis de los parámetros de sostenibilidad y su cumplimiento por las iniciativas adoptadas. Favorecer la competitividad, rentabilidad y sostenibilidad del turismo son los ejes para el programa de desarrollo de la investigación, la innovación y la modernización del sector turístico andaluz; iniciativa que aspira a dotar de un respaldo científico e investigador a un sector que se encuentra en constante evolución.

La aplicación de las nuevas tecnologías, y más específicamente de las redes sociales, ha ido un paso más allá del simple intercambio de información y está asentando un nuevo modelo turístico: el turismo colaborativo. El turista-cliente no se limita a generar información para otros potenciales visitantes, si no que se convierte en generador

\footnotetext{
18 A este respecto, OLCINA CANTOS, J., "Turismo y cambio climático: una actividad vulnerable que debe adaptarse", Investigaciones Turísticas, núm. 4, julio-diciembre, 2012, pp. 1-34.

19 OLCINA CANTOS, J., y VERA-REBOLLO, F., "Cambio climático y política turística en España: diagnóstico del litoral mediterráneo español”, Cuadernos de Turismo, núm. 38, 2016, p. 354.
} 
de negocio; por ejemplo, a través del alquiler de su vivienda para fines turísticos ${ }^{20}$. Este nuevo modelo necesita de un replanteamiento que permita valorar su impacto real en las políticas turísticas. Midiendo la sostenibilidad de estas iniciativas que, en ocasiones, están actuando de forma paralela a los modelos de planificación públicos, y generando perturbaciones desde el punto de vista ambiental, urbanístico, competencial ${ }^{21}$.

\section{g) Segmentos turísticos}

La última de las líneas estratégicas se destina a los segmentos turísticos, y se centra en su desarrollo y complementariedad. Las exigencias actuales del sector turístico se centran en la elaboración de productos turísticos que pongan en alza las potencialidades económicas, culturales, ambientales y sociales del territorio. Un producto complejo, capaz de unificar el recurso turístico, las actividades y los servicios; que exige la implicación de todos los agentes del sector, y ofrece una experiencia turística más completa ${ }^{22}$.

La sostenibilidad de este proceso de diseño y creación de productos turísticos se garantiza a través del respeto a los valores, y la necesaria implicación de la ciudadanía; máxime cuando la tendencia actual del sector se centra en las experiencias completas, en contacto con la realidad del territorio que se visita. Este modelo turístico toma como referencia la integración del turista; que no quiere ser un mero espectador, sino que muestra interés y valora su integración en el territorio que visita, para conocer de primera mano sus recursos y su identidad social y cultural.

El programa de complementariedad entre segmentos, destinos y productos trata de potenciar en el visitante la necesidad de conocer la amplia variedad de recursos naturales, culturales y paisajísticos que ofrece el territorio andaluz. El fin es redistribuir el turismo y la riqueza que genera en toda la Comunidad Autónoma, mediante

20 ROMÁN MÁRQUEZ, A., "Las viviendas particulares dedicadas a la actividad de alojamiento turístico. Su exclusión de la Ley de Arrendamientos Urbanos", Revista Internacional de Doctrina y Furisprudencia, núm. 6, 2014, pp. 1-24.

${ }^{21}$ GUILLÉN NAVARRO, N., e IÑIGUEZ BERROZPE, T., "Acción pública y consumo colaborativo. Regulación de las viviendas de uso turístico en el contexto p2p", PASOS. Revista de Turismo y Patrimonio Cultural, vol. 14, núm. 3, 2016, pp. 763-764.

22 Como señala RIVERA MATEOS, M., "El turismo experiencial como forma de turismo responsable e intercultural”, en RODRÍGUEZ GARCÍA, L., y ROLDÁN TAPIA, R., Relaciones interculturales en la diversidad, Universidad de Córdoba, 2013, p. 213: "Los cambios de hábitos de consumo y de modos de vida de los consumidores se inclinan, en definitiva, hacia unas mayores exigencias en la calidad de sus estancias y viajes, de manera que las nuevas marcas junto con la autenticidad y no masificación y estandarización de los destinos van a ser cada vez más factores dominantes, así como el desarrollo de nuevos mercados a través de productos combinados de entretenimiento, excitación experiencial, educación y contacto más directo y auténtico con la realidad del destino y la cultura y formas de vida de las comunidades locales, lo que puede favorecer las nuevas formas de turismo responsable e intercultural”. 
el diseño de productos y servicios conjuntos que agrupen a varios municipios y puedan comercializarse de forma unificada.

De gran interés es el programa de actuación destinado a la elaboración de un inventario de recursos y productos turísticos; su objetivo es la mejora en la gestión y el acceso a la información sobre los recursos y potencialidades turísticas, para el diseño y creación de productos turísticos integrados. A través de esta iniciativa se trata de aplicar esta información para potenciar la complementariedad de los productos, y conseguir una redistribución de los flujos turísticos.

El fomento de nuevos productos y segmentos turísticos es una oportunidad para trazar un modelo turístico sostenible, que sea capaz de corregir las deficiencias de los productos tradicionales y que ofrezca experiencias únicas y originales al visitante, desde el conocimiento y disfrute de los recursos turísticos naturales y culturales. Uno de los instrumentos más interesantes es el desarrollo de productos personalizados, caracterizados por la sostenibilidad y la calidad de su oferta. En este aspecto, las nuevas tecnologías están llamadas a liderar un nuevo esquema de actuación que permite abrir la oferta a todo tipo de visitantes, con independencia de sus características y limitaciones, a la vez que potencian una visión más completa del destino, que se inicia con la preparación del viaje.

El programa de desarrollo de microproductos y segmentos turísticos emergentes también ofrece una perspectiva muy relevante desde el punto de vista de la sostenibilidad, puesto que en la búsqueda por una mayor especialización en sus viajes, el turista es más exigente y persigue una oferta que responda a sus motivaciones y gustos. A la vista de la riqueza y variedad del patrimonio natural y cultural de la Comunidad Autónoma, la oferta permite la consolidación de segmentos turísticos emergentes, como el turismo ecuestre o el gastronómico, y que ofrecen una perspectiva más sostenible frente a los productos tradicionales; ensalzando valores locales que estarían abocados a la desaparición sin este apoyo del sector turístico.

\section{G. Midiendo la sostenibilidad: El Sistema de Indicadores de Desarrollo Turístico Sostenible.}

El Sistema de Indicadores del Desarrollo Turístico de Andalucía ha sido elaborado por la Empresa Pública para la Gestión del Turismo y el Deporte de Andalucía, y su finalidad es analizar la repercusión del Plan General de Turismo Sostenible y los distintos planes turísticos de él dependientes. A través de estos indicadores se permite la evaluación continuada de las acciones desarrolladas por el Plan, midiendo sus efectos. De esta forma, se trata de ampliar el conocimiento sobre las múltiples 
facetas y caracteres que definen el destino turístico andaluz y su tendencia hacia el desarrollo sostenible.

Para este sistema se han seleccionado las siguientes áreas de carácter transversal y que se consideran esenciales para la valoración de esta planificación: gobernanza, territorio, vulnerabilidad, rentabilidad, diversificación, calidad, e innovación.

Vamos a centrarnos en el aspecto territorial ya que, como se afirma en el Plan, "entendiendo la adecuación del destino como un concepto amplio que rebasa las variables puramente turísticas, la sostenibilidad del destino en gran medida es la sostenibilidad territorial" ${ }^{23}$.

La finalidad de incluir este área en el sistema de indicadores es llevar a cabo una evaluación de la sostenibilidad del territorio en la que se tomen en consideración las relaciones del turismo con el entorno patrimonial, natural, institucional, económico y social; respondiendo a la ya mencionada premisa del Plan de apostar por una visión integral de la sostenibilidad ${ }^{24}$.

Los ámbitos objeto de evaluación en el área de territorio son: cohesión territorial, presión humana, calidad del medio ambiente, protección, uso de recursos, transporte y vivienda, y concienciación. Todos ellos son elementos clave dentro del concepto amplio de sostenibilidad por el que se apuesta en el Plan; por ejemplo, podemos destacar el "uso de recursos", en el que se toman en consideración aspectos básicos para cuantificar el nivel de sostenibilidad en un territorio, como son las emisiones de dióxido de carbono, los residuos o el consumo y depuración de agua. De especial interés nos parece el apartado de "concienciación”, a través del cual se evalúa la percepción social y la educación sobre elementos como las prácticas responsables, la contaminación o los incendios; esenciales por cuanto permiten reflexionar sobre la sostenibilidad futura del territorio, a través del nivel de implicación de la ciudadanía y de las demandas sociales en este ámbito.

23 Hay que tener en cuenta que para la elaboración de estos indicadores se han tomado como referencia la Estrategia Europea de Desarrollo Sostenible, la Estrategia Española de Desarrollo Sostenible y el Sistema de Indicadores Europeo de Turismo para la Sostenibilidad de los Destinos (Toolkit).

24 A propósito de la relación territorio-turismo sostenible, podemos destacar el caso de la Comunidad Autónoma de Canarias, donde se ha llevado a cabo una apuesta por la sostenibilidad desde la legislación urbanística. Como señala RAZQUIN LIZARRAGA en su análisis de las últimas reformas operadas en la legislación canaria sobre esta materia: “(...) a la crisis económica no se puede hacer frente más que mediante un desarrollo sostenible tanto del territorio como del turismo, y además con una clara apuesta por la sostenibilidad porque ésta es la única forma de crear empleo estable y de calidad". RAZQUIN LIZARRAGA, M., "Urbanismo, medio ambiente y turismo. Una integración necesaria y fortalecedora", $X X I$ Congreso Italo-español de Profesores de Derecho Administrativo, Alicante/Benidorm, 26-28 de mayo de 2016, p. 8. 


\section{III.-PLANEAMIENTO ESPECÍFICO}

\section{La Estrategia Integral de Fomento del Turismo Interior Sostenible de Andalucía. Plan +Interior}

En marzo de 2016 se adoptó el texto definitivo de la Estrategia Integral de Fomento del Turismo Interior Sostenible de Andalucía Horizonte $2020^{25}$. El objetivo básico de este instrumento de planeamiento es actuar como directriz principal de las actuaciones destinadas a mejorar el desarrollo económico de las zonas de interior, apostando por aprovechar su potencial turístico y haciendo hincapié en la oportunidad para la creación de empleo.

Desde el punto de vista de su categorización, el Plan +Interior se encuadra dentro de los Marcos Estratégicos para la Ordenación de los Recursos y las Actividades Turísticas; y ostenta, por tanto, la consideración de Plan con Incidencia en la Ordenación del Territorio ${ }^{26}$. Mediante estos planes se trata de desarrollar un modelo turístico aplicable a un territorio concreto, con referencia a los objetivos y estrategias para su concreción, y dentro de las previsiones del Plan General del Turismo.

Los Marcos Estratégicos toman como punto de partida la identificación de los recursos naturales, culturales y paisajísticos que puedan integrarse en el diseño de productos turísticos; a la vez que se incide en la necesidad de su puesta en valor, promoción y uso sostenible.

En el contenido mínimo que la LTA identifica para los Marcos Estratégicos, se incluyen una serie de aspectos que inciden de forma directa sobre la sostenibilidad del modelo turístico propuesto. De esta forma, se ha de incluir una evaluación de la incidencia ambiental del modelo que sea coherente con el desarrollo sostenible, y que incluya previsiones sobre los efectos del cambio climático; además de elaborar una previsión sobre las demandas en materia de infraestructuras, dotaciones y equipamientos. En esta misma línea, se hace referencia a los espacios turísticamente saturados, que puedan necesitar de unos programas de recualificación específicos; así como al establecimiento de criterios para la implantación de campos de golf de interés turístico y otras instalaciones turísticas de alcance territorial.

Desde la Exposición de Motivos del Decreto de aprobación del Plan +Interior, se pone de manifiesto la aspiración de desarrollar un modelo de turismo sostenible, donde se tomen en consideración los aspectos económicos, sociales, culturales y ambientales. Cabe destacar el interés por maximizar los efectos económicos del suelo, y

25 Decreto 77/2016, de 22 de marzo, por el que se aprueba la Estrategia Integral de Fomento del Turismo de Interior Sostenible de Andalucía Horizonte 2020 (BOJA núm. 68, de 12 de abril de 2016).

26 Art. 12 LTA. 
por preservar los recursos naturales, paisajísticos y culturales; además de elementos característicos como el bienestar y la seguridad.

El ámbito de aplicación del Plan comprende más de setecientos municipios del interior de Andalucía; este entorno presenta una serie de caracteres definidores que hacían necesario un instrumento de planeamiento específico. Desde la administración turística autonómica se da respuesta a una petición del sector, y se solventan las deficiencias que se habían puesto de manifiesto respecto a los instrumentos de planeamiento ya adoptados.

Es evidente que los principales destinatarios de este instrumento de planeamiento son los sujetos que participan en el sector turístico, desde los turistas, hasta los trabajadores y empresarios. No obstante, el Plan +Interior también atiende al desarrollo local, potenciando las economías de escala y favoreciendo la consolidación de la población.

El modelo turístico en la zona del interior de Andalucía se ha visto lastrado por la crisis económica, y necesitaba un impulso con el que hacer frente a las nuevas demandas del visitante, a la vez que adoptar medidas para contrarrestar los efectos de la estacionalidad. El contexto en el que se elabora el Plan +Interior determina los aspectos clave sobre los que la administración turística debe fundamentar su política en estos municipios; entre los ejes de actuación podemos señalar la oportunidad de redimensionar el sector, reorganizando los recursos, productos y destinos; impulsar al empresariado a través del soporte y asesoramiento, especialmente en el ámbito tecnológico; mejorar la colaboración público-privada, y actuar sobre la mejora de la sostenibilidad de los espacios turísticos.

La ejecución del Plan +Interior se distribuye en tres fases bianuales. En la primera etapa, que comprende hasta 2018, se llevarán a cabo las iniciativas destinadas a la solución de los problemas estructurales. Mientras que durante las fases intermedia y final se implementarán las iniciativas secundarias, y que exigen la eliminación de las deficiencias de base que presenta el turismo de interior en la Comunidad Autónoma.

a) Lineas estratégicas.

La Estrategia perfila tres líneas estratégicas destinadas a la integración y cohesión territorial, el desarrollo económico y el producto turístico. Se concretan a través de siete programas que comprenden: el apoyo, formación y asesoramiento del sector turístico, la innovación en la gestión, la sostenibilidad del espacio turístico, la reorientación de uso de equipamientos e infraestructuras turísticas del interior, el fomento de la colaboración público-privada, el impulso del producto turístico de interior y la promoción y comercialización del destino Andalucía interior. 
Vamos a centrarnos en el modelo de crecimiento que se prevé en la línea dedicada al desarrollo socioeconómico, y que parte de tres perspectivas centradas en un crecimiento inteligente, sostenible e integrador. Siguiendo las directrices del planeamiento general, ya analizadas, se incide en un sentido "holístico e integral" de la sostenibilidad; si bien, se concretan algunos aspectos referentes a este amplio concepto de sostenibilidad, que ayudan a perfilarlo y a incluir iniciativas de gran interés para la consecución de los objetivos generales.

Resulta llamativa la dimensión pedagógica de la sostenibilidad; llamada, en términos de la Estrategia, a reeducar al sector público y privado y a la ciudadanía acerca de su importancia. Siguen estas previsiones las referencias de la concienciación ciudadana que ya hemos analizado, pero profundizan en la inclusión de los sectores público y privado. Asimismo, se confirma el interés en los modelos de gestión por procesos desde la horizontalidad, integrando a los participantes en la toma de decisiones sobre el modelo socioeconómico del territorio.

Nos encontramos con una referencia expresa y muy clara a la eficiencia energética, la promoción del uso de energías renovables y el fomento del autoconsumo. Además de hacer hincapié en las medidas para la reducción del consumo y la elaboración de planes específicos para controlar el consumo energético.

En materia de movilidad, las propuestas se centran en la implantación de sistemas de transporte limpios, respetuosos con el medio ambiente, y en la mejora de los vínculos urbano-rurales. Y de nuevo, se sitúa el foco en la necesidad de luchar contra el cambio climático y en la adopción de medidas que reduzcan el consumo energético vinculado al transporte. Entre los ejemplos de medidas que se enumeran podemos hacer referencia al fomento de la economía local a través del consumo de productos kilómetro cero y un mercado laboral de proximidad; o la promoción de los caminos naturales a través de la recuperación de las antiguas vías de ferrocarril, como instrumento para el desarrollo del patrimonio natural y cultural.

\section{b) Programas de actuación.}

Entre los programas de actuación destacamos el dedicado a la sostenibilidad del espacio turístico. Desde el texto del Plan +Interior se destaca la especial relevancia de este programa, consecuencia de su orientación hacia la cohesión e integración territorial, y al fomento del desarrollo socioeconómico. Las directrices de actuación de este programa son la movilidad, habitabilidad, implicación social, patrimonio intangible, turismo y medio natural, y paisaje. Llegados a este punto, corresponde señalar la necesidad de coordinar este instrumento de planeamiento con las iniciativas autonómicas en materia de ordenación del territorio, esenciales para integrar el sector turístico en el diseño territorial andaluz. 
La sostenibilidad del espacio turístico es la clave de este programa, que pone el énfasis en los criterios de movilidad, paisajísticos y de accesibilidad ${ }^{27}$. Por ello, la referencia a los itinerarios paisajísticos da respuesta a buena parte de los objetivos de este programa; y comprende las referencias a las carreteras paisajísticas y a la red autonómica de la bicicleta.

\section{Recualificación de Destinos}

La relevancia del turismo en la Comunidad Autónoma de Andalucía ha marcado el desarrollo socioeconómico y territorial de buena parte de su territorio; desde mediados del siglo pasado la llegada masiva de turistas a la región la han convertido en un destino de referencia a nivel internacional y, a la vez, han comprometido la sostenibilidad de los recursos ante la demanda creciente de visitantes.

En este contexto, la LTA incluye entre los instrumentos de planificación una figura destinada a la ordenación de aquellos espacios que se encuentren turísticamente saturados o en peligro de estarlo ${ }^{28}$. Entornos caracterizados por su rápido crecimiento, la fragilidad territorial y ambiental, y la densidad turística, entre otras circunstancias.

Los Programas de Recualificación tienen por finalidad el fomento de la competitividad, el aumento de la calidad, la mejora de las condiciones laborales y la búsqueda de la sostenibilidad. Siguiendo el modelo de los instrumentos de planificación ya analizados, incluyen un diagnóstico turístico-ambiental y el marco financiero.

Uno de los elementos distintivos de estos Programas es la atención por las relaciones interadministrativas; instaurando fórmulas de coordinación, cooperación y colaboración entre las Administraciones Públicas implicadas, además de propuestas para la celebración de convenios para la ejecución de las previsiones del plan.

La participación del nivel municipal es determinante desde las primeras fases, puesto que la norma prevé que la iniciativa para su aprobación se lleve a cabo desde la Junta de Andalucía, o directamente por solicitud de los municipios afectados ${ }^{29}$.

27 JIMÉNEZ HERRERO, L. (dir.), Patrimonio natural, cultural y paisajístico. Claves para la sostenibilidad territorial, Observatorio de la sostenibilidad en España, Madrid, 2009, p. 59: "El interés por el paisaje conecta con aspectos que se refieren a la identidad y al marco vital en el que se desarrollan las personas; por esta razón se afirma que el paisaje forma parte del derecho que cada ser humano tiene a unas condiciones de vida dignas. La atención al paisaje se sustenta así en objetivos básicos de toda sociedad, a los que puede contribuir concretándolos en cada lugar por su reflejo de prácticas que tienen una base natural y que han sido conocidas y utilizadas históricamente. Las políticas de protección y gestión de la naturaleza, las culturales, las económicas y las educativas encuentran en el concepto de paisaje, un hecho útil para su desarrollo y concreción".

28 Art. 14 LTA.

29 Sobre las competencias de los entes locales en el ámbito turístico, BERMEJO VERA, J., "Régimen jurídico de los municipios turísticos", Documentación Administrativa, núm. 259-269, 2001, pp. 226 y ss. 
No obstante, la aprobación corresponderá al Consejo de Gobierno, previa propuesta de la Consejería competente, puesto que nos encontramos ante un instrumentos de ordenación autonómico.

Los Programas de Recualificación se encuentran condicionados en sus previsiones por el contenido de los Marcos Estratégicos para la Ordenación de los Recursos y las Actividades Turísticas, y por el planeamiento general. En lo que respecta a su relación con los planes urbanísticos, la LTA faculta a los Programas para formular recomendaciones sobre ordenación del uso turístico.

La referencia a estos instrumentos estaría incompleta sin la mención al Programa de Recualificación Turística de la Costa del Sol Occidental, el denominado "Plan Qualifica"30. Este plan fue adoptado bajo la vigencia de la anterior norma andaluza en materia urbanística, si bien es un fiel reflejo de la finalidad de estos instrumentos y nos permite poner de manifiesto el recorrido de esta figura y su incidencia sobre el territorio.

Como referente nacional e internacional, y destino maduro por excelencia en la Comunidad Autónoma de Andalucía, la Costa del Sol Occidental fue objeto en el año 2007 de un Programa de Recualificación de Destinos ${ }^{31}$. De esta forma, se trataba de dar respuesta a las demandas del sector turístico y de la sociedad en general, que clamaban desde hacía décadas por una atención específica para un destino de primer nivel y que no había recibido la atención merecida por parte de la Administración autonómica.

La finalidad del Plan Qualifica es la mejora de la calidad y la competitividad del destino; mediante actuaciones sobre el patrimonio y del espacio turístico dirigidas a la sostenibilidad y rentabilidad socioeconómica, y con el objetivo de poner de

A este respecto corresponde recordar que el artículo 9.16 de la Ley 5/2010, de 11 de junio, de Autonomía Local reconoce a los municipios andaluces competencias propias en materia de promoción turística, incluida la promoción de sus recursos turísticos y fiestas de especial interés; la participación en la formulación de los instrumentos de planificación y promoción del sistema turístico en Andalucía; y el diseño de la política de infraestructuras turísticas de titularidad propia.

30 El ámbito de actuación del Plan se centra en los municipios que conforman la Costa del Sol Occidental, en concreto los siguientes: Torremolinos, Benalmádena, Fuengirola, Mijas, Marbella, Estepona, Casares y Manilva.

31 El 6 de Abril de 2006 el Consejero de Turismo, Comercio y Deporte, el Sr. Plata Cánovas, y un destacado número de agentes empresariales, sociales e institucionales, firmaron en Málaga el Acuerdo de Suscripción del documento base para la formulación del Plan de Recualificación Turística de la Costa del Sol Occidental.

Decreto 78/2007, de 20 de marzo, por el que se aprueba el "Plan Qualifica" (BOJA núm. 75, de 17 de abril de 2007). 
relieve las singularidades del ámbito territorial comprendido en este instrumento de planeamiento $^{32}$.

\section{La Estrategia de Turismo Sostenible}

La Estrategia de Turismo Sostenible se destina a desarrollar un sistema de planificación turística estratégica centrado en la oferta turística, o en un producto o segmento turístico específico ${ }^{33}$. Los objetivos que establece la LTA para este instrumento de planificación se centran en la creación o mejora de productos turísticos, el fortalecimiento de la competitividad del sector turístico local, los espacios turísticos, la implantación de acciones de sostenibilidad medioambiental y adaptación al cambio climático, la implantación de modelos de gestión integral de la calidad en los destinos turísticos y su incidencia en el itinerario de consumo turístico, y el desarrollo de actuaciones que favorezcan la accesibilidad turística.

La consecución de los fines de la Estrategia se lleva a cabo a través de dos Iniciativas: Ciudades Turísticas y Turismo Sostenible. Al igual que la Estrategia, las dos Iniciativas se aprueban por Orden del titular de la Consejería competente en materia de turismo.

La Iniciativa de Ciudades Turísticas tiene por objetivo la creación de espacios turísticos en las ciudades medias; específicamente hace referencia la Ley andaluza a las ciudades declaradas por la UNESCO como Patrimonio de la Humanidad. Se trata con esta Iniciativa de fortalecer las rutas culturales o itinerarios turísticos, mediante la oferta de productos atractivos y diseñados sobre los recursos patrimoniales de estas localidades, ya sean de origen natural, monumental o cultural. Por su parte,

32 Como desarrollo de este instrumento, y a fin de profundizar en la cooperación interadministrativa y alcanzar un modelo de desarrollo turístico sostenible, se constituyó en 2008 el Consorcio "Desarrollo y Turismo de la Costa del Sol Occidental"; integrado por el Ministerio de Industria, Turismo y Comercio, la Junta de Andalucía, la Diputación Provincial de Málaga, los Ayuntamientos de Benalmádena, Casares, Estepona, Fuengirola, Manilva, Marbella, Mijas y Torremolinos, así como la Confederación de Empresarios de Andalucía, Comisiones Obreras de Andalucía y la Unión General de Trabajadores de Andalucía. La labor de este Consorcio fue reconocida a principios de 2016 con la Distinción de Honor "Fomento de la investigación en turismo", otorgada por la Facultad de Turismo de la Universidad de Málaga.

Resolución de 17 de diciembre de 2008, de la Dirección General de Administración Local, por la que se acuerda la publicación de los estatutos del denominado "Consorcio de Desarrollo y turismo de la Costa del Sol Occidental” (BOJA núm. 31, de 16 de febrero de 2009).

33 Art. 13 LTA. Mediante Orden de 18 de mayo de 2011 (BOJA núm. 105, de 31 de mayo de 2011) se desarrolló la Estrategia de Turismo Sostenible y se reguló el procedimiento de selección de los Programa de Turismo Sostenible. Esta Orden se completa con la Resolución de 24 de mayo de 2011, mediante la que se aprueba el formato para el diseño y presentación de los Programas de Turismo Sostenible (BOJA núm. 112, de 9 de junio de 2011). 
la Iniciativa de Turismo Sostenible se destina a espacios con un destacado potencial turístico gracias a un patrimonio natural o cultural de gran interés.

Los Programas de Turismo Sostenible son los ejes sobre los que se desarrollan las Iniciativas de Turismo Sostenible y de Ciudades Turística. Los Promotores de Turismo son los responsables de la elaboración de los Programas, diseñados con el referente último del principio de sostenibilidad de la actividad turística y de los recursos turísticos.

\section{Planes Turísticos de Grandes Giudades.}

El turismo urbano es un sector en alza, por ello, el legislador autonómico optó por incluir un instrumento específico para su regulación en la normativa vigente: los Planes Turísticos de Grandes Ciudades ${ }^{34}$.

Los objetivos generales de estos Planes se centran en la puesta en valor y uso de los recursos turísticos, la accesibilidad universal, el aumento de la calidad, la mejora e innovación de los productos turísticos, la sensibilización e implicación de la población y agentes locales en una cultural de calidad turística, y el fortalecimiento de la competitividad.

La necesidad de elaborar actuaciones específicas para el fomento del turismo urbano parte de la singularidades que presenta frente a otros modelos turísticos y, especialmente, de su escasa estacionalidad, lo que permite contrarrestar una de las principales debilidades del sector turístico andaluz.

Son los municipios, a través de sus Ayuntamientos, los sujetos legitimados para solicitar la formulación de un Plan de Grandes Ciudades. Cualquier municipio andaluz cuya población supere los 100.000 habitantes, y que no tenga vigente algún plan turístico de grandes ciudades concertado con la Administración autonómica, podrá presentar esta solicitud. Los Planes Turísticos de Grandes Ciudades se articulan mediante convenios de colaboración entre la Consejería competente y la Administración local.

La memoria justificativa que tienen que elaborar los Ayuntamientos debe incluir un diagnóstico del contexto turístico de la localidad, así como una valoración sobre la oportunidad y conveniencia para la elaboración de este plan turístico. A la

34 Art. 15 LTA. Mediante el Decreto 146/2016, de 30 de agosto, por el que se regulan los Planes Turísticos de Grandes Ciudades de Andalucía y los convenios de colaboración mediante los que se articulan (BOJA núm. 173, de 8 de septiembre de 2016), se han definido los requisitos que han de reunir los municipios que pueden ser objeto de Planes Turísticos de Grandes Ciudades, se ha regulado el procedimiento de formulación, así como de aprobación de los Planes, y se ha establecido el contenido de los convenios de colaboración. 
que debe adjuntarse una descripción de las iniciativas que deberían desarrollarse en el plan, tomando como punto de partida las directrices y objetivos del Plan General del Turismo de Andalucía. Desde la perspectiva económica, se elabora una estimación de la inversión necesaria, así como el compromiso de colaborar en la financiación del plan, al menos en un 50\% de la inversión total, y la constatación de su previsión presupuestaria.

Una vez que la solicitud es remitida a la administración autonómica, el primer órgano que la recibe y analiza es la Delegación Territorial; que también solicitará los informes oportunos a las Consejerías con competencia en materia de cultura y medio ambiente. El expediente completo, incluido el informe de la Delegación, será remitido a la Secretaría General competente en materia de turismo, responsable de la instrucción y resolución del procedimiento. La resolución estimatoria implicará la formulación del Plan y reconocerá expresamente la participación activa del municipio. La Consejería será la responsable de elaborar y aprobar el Plan, previo informe del Consejo Andaluz del Turismo.

Los convenios de colaboración han de ser suscritos entre el titular de la Consejería y el titular del órgano competente de la Administración local. Entre los aspectos mínimos que habrán de comprender estos convenios se encuentran las actuaciones a realizar por cada parte y la titularidad de los resultados obtenidos; las obligaciones y compromisos económicos, con indicación de su distribución temporal por anualidades y su imputación concreta al presupuesto correspondiente; las consecuencias aplicables en caso de incumplimiento; el régimen de modificación y el plazo de vigencia; y los mecanismos de seguimiento, vigilancia y control de la ejecución del convenio.

\section{V.-CONGLUSIONES}

Los instrumentos de planificación turística en la Comunidad Autónoma de Andalucía han sufrido una clara evolución en los últimos años, marcando un claro viraje en su apuesta por la sostenibilidad. Es destacable como el concepto de sostenibilidad también se ha enriquecido, puesto que partiendo de una acepción claramente relacionada con la conservación y preocupación ambiental, se ha llegado hasta una concepción amplia en la que se comprenden aspectos que van desde la gobernanza o la movilidad, hasta la ciudadanía, sin olvidar los recursos ambientales, culturales, paisajísticos, etc.

Los planes turísticos han estado marcados por la necesidad de complementar a un sector que comenzó su andadura de la mano de la iniciativa privada, en exclusiva; y que se ha convertido en el pilar socioeconómico de Andalucía. Esta realidad ha marcado el devenir de la ordenación administrativa sobre esta materia, condiciona- 
do por la presión del sector empresarial, la población local y las propias demandas de los turistas y visitantes de la región.

La atención a la población local es uno de los aspectos más interesantes de esta concepción; la sostenibilidad turística pasa por la implicación de la ciudadanía en el modelo turístico planificado por los poderes públicos. Esta concepción amplia de la sociedad en relación al turismo, supera a los actores directos de esta actividad y supone que toda la población andaluza debe ser consciente de su relevancia en la aplicación de las políticas desarrolladas por las Administración turística.

El visitante no es el único que ha de sentirse satisfecho con la experiencia turística, es la población local quien también se ha de sentir representada y respetada por el modelo turístico desarrollado. En un estado de evolución del sector turístico en el que las experiencias y la inmersión del turista en la cotidianidad de las localidades visitadas, constituyen la base para el diseño y comercialización de los productos turísticos, la acogida del ciudadano es esencial y marcará la diferencia sobre el resultado de la visita y la valoración final que reciba.

Los instrumentos de planificación analizados tratan de dar respuesta a este fenómeno desarrollando políticas de variada naturaleza y que apuestan por la concienciación ciudadana. Sin embargo, son medidas concretas como la mejora de las infraestructuras, y el apoyo a los destinos más turísticos de la Comunidad para que puedan gestionar mejor los flujos de visitantes, las demandas que realmente deben ser satisfechas a corto plazo. En este sentido, la actuación es urgente, no es una medida que pueda esperar a ser satisfecha en un periodo medio o largo; en los principales destinos turísticos de Andalucía es importante ofrecer una respuesta inmediata a este elemento de sostenibilidad.

La masificación es uno de los principales desafíos de la sostenibilidad turística; a la vez que va aparejada a uno de los grandes problemas del sector en la Comunidad Autónoma de Andalucía, como es la estacionalidad. La gestión del turismo exige una ordenación racional del número de visitantes que puede realmente albergar un destino; lo que exige iniciativas que aborden los nuevos desafíos, como los planteados por el turismo colaborativo. De lo contrario, nos encontraremos con ciudades-escaparate que albergarán a grupos de visitantes que no serán capaces de disfrutar de los recursos ambientales, culturales y, de toda índole, que les ofrece el destino; es más, pondrán en peligro la conservación de este patrimonio.

En este sentido, también corresponde formar a los profesionales del sector turístico sobre la relevancia de la sostenibilidad, y en la apuesta por un modelo turístico de calidad, competitivo, y que sea capaz de respetar y poner en valor los recursos de 
la Comunidad. Por tanto, junto a la necesaria formación en el ámbito de las nuevas tecnologías, corresponde la formación en sostenibilidad; concienciando sobre todos los aspectos de esta visión amplia por la que se apuesta en el vigente Plan General de Turismo Sostenible. Especial interés presenta la accesibilidad y su integración como una pauta determinante por parte del empresariado turístico; abriendo el destino Andalucía hacia cualquier visitante, y favoreciendo que pueda disfrutar de todas las bondades del patrimonio de la Comunidad, sin que existan limitaciones ni barreras que puedan obstaculizar su experiencia.

La implicación del sector privado en el modelo turístico y su compromiso con la sostenibilidad son esenciales para que se materialicen los objetivos de los planes analizados. Esta implicación se inicia desde las fases de diseño y elaboración, y se ha de mantener a lo largo de todas las etapas de aplicación, incluida la evaluación final sobre su efectiva operatividad. La madurez del destino Andalucía también se ha logrado gracias a un mayor grado de sensibilidad del empresariado en la consecución de un turismo sostenible; de hecho, en ocasiones, ha sido el propio sector privado el que ha animado a la administración autonómica a desarrollar iniciativas para la mejora del modelo turístico andaluz.

Un destacado número de los planes analizados parten de esta filosofía de cooperación público-privada, que se completa con la colaboración interadministrativa; integrando a todos los sectores administrativos que de forma directa o indirecta participan en el sector turístico, y abogando por unas líneas de actuación claras y directas que eviten las superposiciones y duplicidades, y favorezcan la inversión de las distintas administraciones públicas implicadas.

La consecución de un modelo turístico sostenible no es uno más de los objetivos de la política turística autonómica, si no que la sostenibilidad ha de forma parte inescindible de los caracteres definidores del turismo en Andalucía. Los ejes teóricos se encuentran trazados en los planes analizados, y los programas de actuación que los concretan también los incorporan y los enarbolan como principio básico en su aplicación. Sin embargo, y a pesar de que hace años que la sostenibilidad se incluye en las actuaciones de planeamiento de la Comunidad, aún queda recorrido para que se incorpore de forma natural y cotidiana en cualesquiera de las actuaciones vinculadas al sector turístico. A través de los instrumentos de seguimiento y evaluación del planeamiento vigente habrá de confirmarse si las previsiones teóricas logran incorporarse de forma paulatina a la práctica turística. 


\section{VI.-BIBLIOGRAFÍA}

BAUZÁ MARTORELL, F., "Intervención administrativa, turismo y medios técnicos", XXI Congreso Italo-español de Profesores de Derecho Administrativo, Alicante/Benidorm, 26-28 de mayo de 2016.

BERMEJO VERA, J., "Régimen jurídico de los municipios turísticos", Documentación Administrativa, núm. 259-269, 2001.

BLANQUER CRIADO, D., “¿Ordenación o desordenación del turismo?” Documentación administrativa, núm. 259 - 260, 2001.

BOUAZZA ARIÑO, O., "Criterios para un desarrollo territorial sostenible del turismo", El derecho urbanístico del siglo XXI: Libro homenaje al profesor Martín Bassols Coma, vol. 2, Editorial Reus, Barcelona, 2008.

CEBALLOS MARTÍN, M., y PÉREZ GUERRA, R., "Aproximación evolutiva en la protección de los recursos naturales y culturales a través de la legislación turística”, en RODRÍGUEZ ARANA MUÑOZ, J., y DEL GUAYO GASTIELLA, I., Panorama jurídico de las administraciones públicas en el siglo XXI: Homenaje al profesor Eduardo Roca Roca, Instituto Nacional de Administración Pública, Madrid, 2002.

GUILLÉN NAVARRO, N., e IÑIGUEZ BERROZPE, T., "Acción pública y consumo colaborativo. Regulación de las viviendas de uso turístico en el contexto p2p", PASOS. Revista de Turismo y Patrimonio Cultural, vol. 14, núm. 3, 2016.

HILDENBRAND SCHEID, A., "La Estrategia de Paisaje de Andalucía y el turismo", Curso de Verano: La sostenibilidad de los entornos turísticos, Universidad de Málaga, 2012.

JIMÉNEZ HERRERO, L. (dir.), Patrimonio natural, cultural y paisajistico. Claves para la sostenibilidad territorial, Observatorio de la sostenibilidad en España, Madrid, 2009.

JIMÉNEZ SOTO, I., "Ordenación de los servicios turísticos: competencias administrativas y unidad de mercado", XXI Congreso Italo-español de Profesores de Derecho Administrativo, Alicante/Benidorm, 26-28 de mayo de 2016.

JORDANO FRAGA, J., "Competencias sobre medio ambiente, espacios protegidos y sostenibilidad (Comentario al artículo 57)", en MUÑOZ MACHADO, S., y REBOLlO PUIG, M., (Coords.), Comentarios al Estatuto de Autonomía para Andalucía, Aranzadi, Cizur Menor (Navarra), 2008.

OLCINA CANTOS, J., "Turismo y cambio climático: una actividad vulnerable que debe adaptarse", Investigaciones Turísticas, núm. 4, julio-diciembre, 2012. 
OLGINA GANTOS, J., y VERA-REBOLLO, F., "Cambio climático y política turística en España: diagnóstico del litoral mediterráneo español”, Cuadernos de Turismo, núm. 38, 2016.

PÉREZ GUERRA, R., "La intervención administrativa en el sector turístico español: La política turística", Revista Aragonesa de Administración Pública, núm. 43-44, Zaragoza, 2014.

RAZQUIN LIZARRAGA, M., "Urbanismo, medio ambiente y turismo. Una integración necesaria y fortalecedora", XXI Congreso Italo-español de Profesores de Derecho Administrativo, Alicante/Benidorm, 26-28 de mayo de 2016.

RIVAS GARCíA, J., y MAGADÁN DÍAZ, M., Planificación y Gestión Sostenible del Turismo, Septem Ediciones, Oviedo, 2015.

RIVERA MATEOS, M., "El turismo experiencial como forma de turismo responsable e intercultural”, en RODRÍGUEZ GARCÍA, L., y ROLDÁN TAPIA, R., Relaciones interculturales en la diversidad, Universidad de Córdoba, 2013.

ROMÁN MÁRQUEZ, A., "Las viviendas particulares dedicadas a la actividad de alojamiento turístico. Su exclusión de la Ley de Arrendamientos Urbanos", Revista Internacional de Doctrina y furisprudencia, núm. 6, 2014.

SOCÍAS CAMACHO, J., "Planificación territorial, medio ambiente y turismo: hacia un turismo sostenible", XXI Congreso Italo-español de Profesores de Derecho Administrativo, Alicante/Benidorm, 26-28 de mayo de 2016.

SORET LAFRAYA, P., y BARRAGÁN ITURRIAGA, A., "Turismo accesible y legislación", Estudios Turísticos, núm. 203-204, 2015. 